\title{
Challenges of online learning during the COVID-I9 pandemic encountered by students in Pakistan
}

\author{
Abaid Ullah', Mahmoona Ashraf',2, Shanza Ashraf'and Sajjad Ahmed' \\ I University of Punjab, Pakistan; ${ }^{2}$ Institute of Education and Research, Pakistan \\ Correspondence should be addressed to Mahmoona Ashraf (iD) mahmoonaashrafl@gmail.com \\ Received 21 November 2020; Revised 24 January 202I; Accepted I5 February 202I
}

\begin{abstract}
This paper aims to identify the challenges faced by Pakistani students during online learning environment, to determine whether a difference exist between males and females students regarding challenges faced during online learning, and to evaluate the effectiveness of online learning in Pakistan from students' perspectives. The population of the present study was consisted of students who were taking online classes in Lahore Pakistan. The study design was cross sectional and analytic study. A sample of 550 students was drawn. The technique of simple random sampling was used for this purpose. Google form questionnaire was used as a tool for data collection. Frequency table were used to represent the findings. One Sample t-test applied regarding problem faced by students in online learning, Independent Sample t-test regarding difference between male and female students responses about challenges faced during online education and One way ANOVA for significant difference between qualification level of students responses about challenges faced during online education. Results revealed that all the students were facing same issues either they were school level or university level. Male and female students were facing same challenges in online classes. Online learning cannot produce good results in developing countries like Pakistan, where a huge majority of students are not able to access the good internet facility due to technical as well as financial issues. This study addressed the effectiveness of online and challenges faced by students who are taking online classes. As per this study, $88 \%$ of students had not proper internet facility and they faced lots of internet issues and $65 \%$ students were not satisfied with online learning $85 \%$ students complaining about eye sight issue by taking online classes on devices $50 \%$ students were unable to manage the university affairs. As a result, we found that all the students were facing same issues either they were school level or university level. We also obtained that male and female students were facing same challenges in online classes.
\end{abstract}

Keywords: COVID-19, challenges, effectiveness, online learning

\section{Introduction}

The World Health Organization (WHO) declared COVID-19 as a global public health emergency of international concern on 30th January 2020 as well as a pandemic on II th March 2020. The first two cases of COVID-19 in Pakistan were confirmed by the Federal Health Ministry in Islamabad and Karachi on 26th February 2020 (Saqlain et al., 2020). As of 19th June 2020, the total numbers of cases of COVID-19 in the country were 165,062 with 3,229 deaths (COVID-19 Stats, 2020). In reaction to the COVID-I9, Pakistani authorities closed all educational institutions across the country on I3th March 2020 (Ali, 2020). As per the orders given by the Federal Government of Pakistan, the Higher Education Commission (HEC) issued directives to higher education institutions to start preparing for distance learning (DL) modes, reschedule the ongoing exams and assist their students online regularly until the COVIDI9 crisis remains unchanged (Ali, 2020). Online education is a form of education where students use their home computers through the internet staying away academic institutions. In recent time, online teaching learning has become a buzz word in the field of education as finding no other alternatives to providing education to the students in the class. Due to the emergence of the pandemic of COVID-19, the whole world is experiencing huge death toll along with widespread panic and uncertainty. Countries of the world are trying to avoid the gap and minimize the losses of students caused by the ongoing pandemic. However, the outcomes of online education are not always a blessing to the learners 'community as revealing a number of pitfalls to the context of online teaching and learning resulting in wide spread concerns over the controversial issue of teaching learning online education during COVID - 19. With the consideration to the fact the present study tries to illustrate the challenges and possibilities of the countries which are not as advanced in technology as the countries blessed with high technology. 
The unexpected change to online learning became a measure of organizational agility ( $\mathrm{Wu}, 2020)$, with several academic institutions primarily focused on the transfer of educational content to the digital world and not specifically on online teaching and delivery methods. Nonetheless, it was a reminder of the lack of resources in academic institutions and the social marginalization of students, where insufficient access and availability of the internet and the lack of latest technology affected organizational responsiveness and students' capacity to participate in digital learning (Karademir et al., 2020; Zhong, 2020). Lack of proper interaction with instructors is another major concern associated with online learning. Additionally, concerns regarding any content of the online course are usually discussed with the relevant course instructor by e-mail, which requires response time (Zhong, 2020). Virtual classes cannot be of interest to students who are tactile learners. Conventional classroom socialization is another major missing in online learning. Students only communicate with their fellows digitally and never see fellow students in person, and thus the real-time sharing of ideas, knowledge and information is partially missing from the digital learning world. The current circumstances are unique; unlike normal digital learning situations, as some might argue, it is online education at tertiary context of Pakistan. Like other countries educational institutions, Pakistan has been shut down where social distancing matters. The government of Pakistan by watching the loss of students in education encouraged the online learning system for students to secure their time and future. Online education has been mainly focused at higher level of education in the country. In Pakistan, unsurprisingly, many parents have turned away from the system. There are roughly 68,000 private schools in Pakistan (about one-third of all schools), up from 49,000. Private money currently pays for more of Pakistan's education than the government does. There are a total of II 4 medical colleges in Pakistan, 44 of which are public and 70 private. In these unprecedented days online teaching learning is the only way of solving academic crisis happening across the globe due to the pandemic of coronavirus Challenge

It is the first time in Pakistan the online trend of education has been introduced at a wide scale but in regard to teaching learning along with assessments this online trend has meanwhile encountered some avoidable circumstances that were also referred to the previous literature. According to William, Cameron and Morgan (20I2) in regard to online education assessment, practices are limited in the variety and modes in which they are allocated in online environment. Data reveal as expressed by students and teachers regarding online classes that they are experiencing a number of challenges. First of all, it is their first experience to get connected with online class, so they are found to be struggling with the proper adaptability with this trend as switching from traditional classroom to computer-based training in a virtual classroom makes the learning and teaching experience entirely different for them. Secondly, during the shutdown most of the students are staying home in different areas of the country as still in the rural areas internet facilities are hardly found, students use mobile internet which interrupts the online connectivity due to poor internet signal. Besides the internet is still expensive in our country. Thirdly, there are some technical issues like poor literacy on handling computer and smart phone. Moreover, students and teachers have to download some applications like zoom and google chat, etc. Sometime seem challenging due to not having prior experiences and these aps have limited time to be connected online. Fourthly, time management has been a crucial thing as for example Zoom can each time connect people online for $\mathbf{4 0}$ minutes but students take time to respond to the class due to some technical interruptions. When students join at the middle of the class, have the chance to understand a little. Fifthly, it is difficult for the teachers to manage feedback from every individual as well as to let them engaged in materials. According to Jaques and Salman (2007) adapting to online environment can be a challenge for both facilitators and students.

The expensive nature of the Internet and the accessibility of technology have generated a surge in the demand for web based teaching and learning. Online education is quickly infiltrating into school districts and colleges across the nation. This study explores whether high school students could benefit from online courses and examines the potential challenges and drawbacks of online coursework. This study raises questions about how to best support high school students enrolled in an online course, which is emphasized before (Gilbert, 20I5).

Adnan and Anwar (2020) examined the attitudes of Pakistani higher education students towards compulsory digital and distance learning university courses amid Coronavirus (COVID-19). Undergraduate and postgraduate were surveyed to find their perspectives about online education in Pakistan. The findings of the 
study highlighted that online learning cannot produce desired results in underdeveloped countries like Pakistan, where a vast majority of students are unable to access the internet due to technical as well as monetary issues. The lack of face-to-face interaction with the instructor, response time and absence of traditional classroom socialization were among some other issues highlighted by higher education students.

Another study claim that during the lockdown period, around $70 \%$ of learners were involved in e-learning. Most of the learners were used android mobile for attending e.learning. Students have been facing various problems related to depression anxiety, poor internet connectivity, and unfavorable study environment at home. Students from remote areas and marginalized sections mainly face enormous challenges for the study during this pandemic. This study suggests targeted interventions to create a positive space for study among students from the vulnerable section of society. Strategies are urgently needed to build a resilient education system in the state that will ensure to develop the skill for employability and the productivity of the young minds.

Consequently, this research identified the challenges faced by students in online learning during pandemic. In this regard, the objectives of the study were to:

i) Identify the challenges faced by students during online learning.

ii) Identify the difference between males and females students regarding challenges faced during online learning.

iii) Determine the effectiveness of online learning in Pakistan from students' perspectives.

The study also seeks the ansfer for the following hypotheses:

$\mathrm{H}_{0} \mathrm{I}=$ There is no problem faced by students in online learning

$\mathrm{H}_{0} 2=$ There is no significant difference between male and female students responses about challenges faced during online education?

$\mathrm{H}_{0} 3=$ There is no significant difference between educational level of students responses about challenges faced during online education?

\section{Method}

\section{I. Research Design}

In order to obtain information correctly, this research adopts a descriptive research design which involves describing the behavior of the research variable without Influence it in any way. In addition, this research adopts a survey research design in the quantitative research, in which researchers conducted a survey to sample the entire population to describe their attitudes, the opinions, behaviors or characteristics of the respondents. In addition, researchers use questionnaires (mailed questionnaires) to collect quantitative data then perform statistical analysis on the data to test the research question or hypothesis.

The survey is divided into two main types of census and sample survey. In the census, the survey shows that researchers can collect data from every member of the population without leaving anyone. In a sample survey, the data collected from part of the population summarizes the intent of the research results. Most survey research designs are Non-experimental, used to evaluate the statistical relationship between variables or describe a single variable. Cross-sectional surveys collect data one at a time. Longitudinal surveys collect data from the same target population at different times.

In order to conduct this research, a cross-sectional survey research design was adopted. Cross-sectional studies include observation samples or the entire study population or Phenomenon at a certain point in time. However, this study is used cross-sectional survey design and employed to explore challenges in online learning faced by students who were taking online classes during pandemic.

\subsection{Population and Sample}

The target population of this study was the students taking online classes in Pakistan. Random samples selected from the educational institutes of Lahore, Pakistan. Among the targeted popularion, 550 students were 
randomly selected since a simple random sampling was applied. Online survey via Google form was taken as a tool of data collection. Figure I shows the characteristics of the participants.

Figure I

Characteristics of the participants

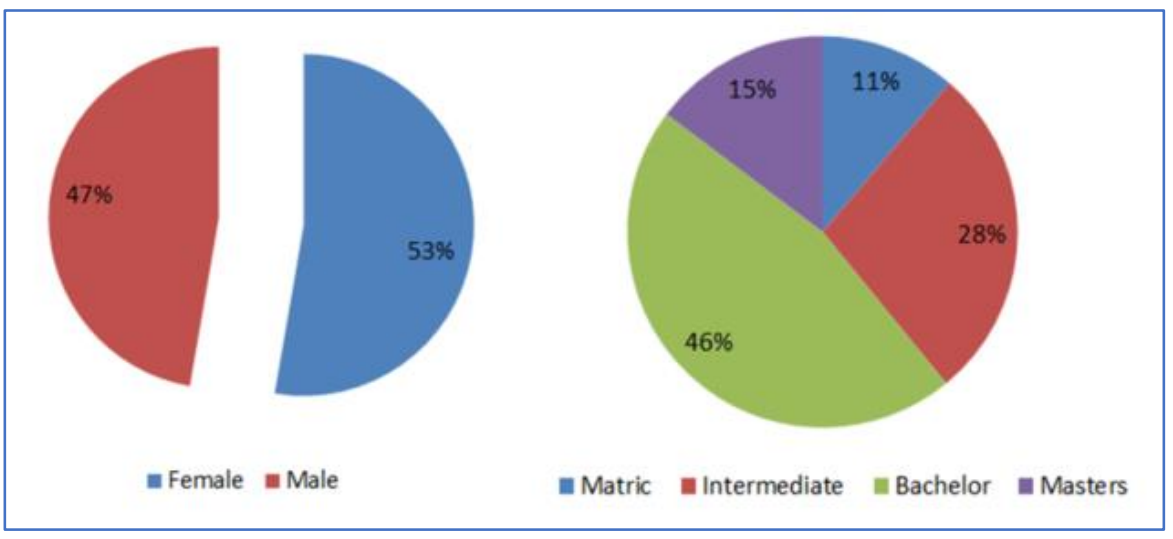

As can be seen in Figure I, it is seen that the majority of 550 participants have the highest bachelor degree, and female gender.

\subsection{Instruments}

A self-constructed questionnaire was designed and organized. First section was Background information about the respondents and was divided into sub sections, Age, University/college name, Qualification (Educational level), second section was about the challenges in online learning faced by students. Different types of scales were used in the study. i.e Dichotomous scale, Category scale, and Nominal scale. The analysis used in this research was correlations to find the relationships between variables. After that, we tested the reliabilities of all the variables to check the internal consistency of the constructs. The population of the study was students which were taking online classes of Lahore, Pakistan. The sample size of 550 was taken. Simple random sampling was applied to sampling. Online survey via Google form was taken as a tool of data collection. The Cronbach's alpha statistics $(0.80)$ showed that the reliability value of instrument's data set was good and reliable questionnaire validated by the experts.

\subsection{Data Analysis}

SPSS I5.0 was used to analysis for the collected data and to assess the demographic profile of the sample as well as the internal consistency of the construct. Participants' responses to the items of the scale were presented descriptively, primarily in percentage and frequencies. Afterwards, since the normality test performed before comparing the groups showed that the data sets were normally distributed, the t-test was performed.

\section{Results}

In this section, the data obtained are presented descriptively and the general picture is presented. Afterwards, relational analyzes were included within the framework of the sub-objectives of the study.

The summary of the responses given by the participants to the items in the scale is shown in Table I.

Table I

Descriptive statistics of participants' frequency and percentage of responses

\begin{tabular}{|c|c|c|c|}
\hline No & Factors & Yes & No \\
\hline 0I & Is online learning is good for students? & $\begin{array}{c}191 \\
(347 \%)\end{array}$ & $\begin{array}{c}359 \\
(653 \%)\end{array}$ \\
\hline 02 & $\begin{array}{l}\text { Mobile phone has become one of the most popular devices among students for } \\
\text { online learning as compared to Laptops and Tablets. }\end{array}$ & $\begin{array}{l}416 \\
(75.6 \%)\end{array}$ & $\begin{array}{l}134 \\
(24.4 \%)\end{array}$ \\
\hline
\end{tabular}


Table I continued

\begin{tabular}{lcc}
\hline Factors & Yes & No \\
\hline Time management is a difficult task for online learners & 411 & 139 \\
Do you feel that teacher is well prepared of the lectures which have been & $(74.7 \%)$ & $(25.3 \%)$ \\
delivered to you? & 299 & 251 \\
Do you feel comfortable while taking online classes? & $(54.4 \%)$ & $(45.6 \%)$ \\
& 183 & 366 \\
Do teachers available on the given time? & $(33.3 \%)$ & $(66.7 \%)$ \\
& 357 & 193 \\
Is there any miss-management faced by you during online learning? & $(64.9 \%)$ & $(35.1 \%)$ \\
& 357 & 193 \\
Pandemic condition increased student's self-confidence? & $(64.9 \%)$ & $(35.1 \%)$ \\
& 207 & 343 \\
Online learning enhanced student's ability to improve their learning skill? & $(37.6 \%)$ & $(62.4 \%)$ \\
& 174 & 376 \\
Online study system is valid for all students in this miserable situation? & $(31.6 \%)$ & $(68.4 \%)$ \\
& 272 & 278 \\
Online learning during a pandemic condition effects the eye sight of a student? & $(49.5 \%)$ & $(50.5 \%)$ \\
& $(868.1 \%)$ & $(14.9 \%)$ \\
Students improved their social skills in online learning? & 269 & 281 \\
Pandemic condition modernized the evaluation and assessment Technology for & $(48.9 \%)$ & $(51.1 \%)$ \\
students? & 367 & 183 \\
Lots of internet problems faced by the students in pandemic condition? & $(66.7 \%)$ & $(33.3 \%)$ \\
Pandemic condition built up student's capacity, to manage their schools, & 487 & 63 \\
Colleges and Universities affairs? & $(88.5 \%)$ & $(11.5 \%)$ \\
Online learning could be applicable further in Pakistan? & 279 & 271 \\
& $(50.7 \%)$ & $(49.3 \%)$ \\
\hline
\end{tabular}

Table I shows that the frequency and percentage of the respondents when different questions were asked from the researcher side about challenges faced during online learning. Out of the 550 respondents 191 (34.7\%) answered yes and $359(65.3 \%)$ were answered no that Is online learning is good for students? Out of the 550 respondents $416(75.6 \%)$ answered yes and 134 (24.4\%) were answered no that Mobile phone has become one of the most popular devices among students for online learning as compared to laptops and tablets, Out of the 550 respondents $4 \mathrm{II}$ (74.7\%) answered yes and I 39 (25.3\%) were answered no that Time management is a difficult task for online learners, Out of the 550 respondents 299 (54.4\%) answered yes and 25I (45.6\%) were answered no that you feel that teacher is well prepared of the lectures which have been delivered to you, Out of the 550 respondents 183 (33.3\%) answered yes and $366(66.7 \%)$ were answered no that Do you feel comfortable while taking online classes? Out of the 550 respondents $357(64.9 \%)$ answered yes and $193(35.1 \%)$ were answered no that do teachers available on the given time? Out of the 550 respondents $357(64.9 \%)$ answered yes and $193(35.1 \%)$ were answered no that is there any miss-management faced by you during online learning, Out of the 550 respondents 207 (37.6\%) answered yes and 343 (62.4\%) were answered no that Pandemic condition increased student's self-confidence, Out of the 550 respondents $285174(31.6 \%)$ answered yes and $376(68.4 \%)$ were answered no that Online learning enhanced student's ability to improve their learning skill? Out of the 550 respondents $272(49.5 \%)$ answered yes and $278(50.5 \%)$ were answered no that Online study system is valid for all students in this miserable situation? Out of the 550 respondents $468(85.1 \%)$ answered yes and 82 (14.9\%) were answered no that Online learning during a pandemic condition effects the eye sight of a student? Out of the 550 respondents $269(48.9 \%)$ answered yes and $28 \mathrm{I}(5 \mathrm{I} .1 \%)$ were answered no that Students improved their social skills in online learning? Out of the 550 respondents $367(66.7 \%)$ answered yes and 183 (33.3\%) were answered no that Pandemic condition modernized the evaluation and assessment Technology for students? Out of the 550 respondents 487 (88.5\%) 
answered yes and 63 (11.5\%) were answered no that Lots of internet problems faced by the students in pandemic condition? Out of the 550 respondents 279 (50.7\%) answered yes and 27I (49.3\%) were answered no that Pandemic condition built up student's capacity, to manage their schools, Colleges and Universities affairs? Out of the 550 respondents 202 (36.7\%) answered yes and 348 (63.3\%) were answered no about Online learning could be applicable further in Pakistan.

On the other hand, the tested hypotheses are presented below. The results obtained from the first hypothesis tested are presented in Table 2.

Table 2

One Sample t-test regarding problem faced by students in online learning

\begin{tabular}{|c|c|c|c|c|c|c|}
\hline Variable & $\mathbf{N}$ & $M$ & $S D$ & $d$ & $d f$ & $p$ \\
\hline $\begin{array}{l}\text { Challenges } \\
\text { faced by }\end{array}$ & 550 & 22.34 & 3.707 & $14 \mid .32$ & 549 & 0.000 \\
\hline
\end{tabular}

One sample t-test applied to find out the problem faced by students in online learning. As $P<\alpha$ value of $P$ $(0.000)$ is less than the level of significance $\alpha(0.05)$, so our null hypothesis that "There is no problem faced by students in online learning" is rejected. Therefore, it is concluded that there are so many problems faced by students in online learning. The results regarding whether the problems experienced in terms of the gender variable create a difference or not are summarized in Table 3.

Table 3

Independent Sample t-test regarding difference between male and female students responses about challenges faced during online education.

\begin{tabular}{llllllll}
\hline Variables & Gender & $\mathbf{N}$ & $\mathbf{M}$ & $\mathbf{S D}$ & $\boldsymbol{t}$ & $\mathbf{d f}$ & $\boldsymbol{P}$ \\
\hline Challenges faced by students & Female & 385 & 22.53 & 3.69 & 1.879 & \multirow{2}{*}{548} & \multirow{2}{*}{0.825} \\
& Male & 165 & 21.89 & 3.70 & 1.878 & & \\
\hline
\end{tabular}

An independent sample t-test was applied to find the gender based mean difference in the responses about challenges faced during online education. The results revealed that gender does not significantly affect in viewpoint towards students responses about challenges faced during online education, as $t=1.87, p=.825$ is $>0.05$. It is concluded that both male and female students have shown almost similar perspective towards challenges faced during online education. Finally, we tested whether a difference exist between educational level of students responses about challenges faced during online education. The results are as in Table 4.

Table 4

One way ANOVA for significant difference between educational levels of student's responses about challenges faced during online education

\begin{tabular}{lccccc}
\hline & Sum of Squares & $\boldsymbol{d f}$ & Mean Square & $\boldsymbol{F}$ & Sig. \\
\hline Between Groups & 706.562 & 3 & 235.521 & 18.796 & 0.000 \\
Within Groups & 6841.491 & 546 & 12.530 & & \\
Total & 7548.053 & 549 & & & \\
\hline
\end{tabular}

Table describes that the $F$-value 18.796 with $p=0.000$, is statistically significant at alpha standard level of significance $(\alpha<.05)$ difference between educational level of students responses about challenges faced during online education. There is significant difference between educational level of students responses about challenges faced during online education. As educational level of respondent depends upon the challenges faced by students during pandemic in online classes, students of lower level classes faced more challenges than the students of higher classes. So our Hypothesis "There is no significant difference between educational level of students responses about challenges faced during online education" is rejected. 


\section{Discussion and Conclusion}

COVID-19 effected the physical learning method of all the educational institutions overall the world. The higher authorities of academic institutes adopted online learning to continue the studies. Although online learning seems useful in protecting students' and faculty's health amid COVID-19 pandemic, however, some researchers pointed out that it may not as productive as expected (Kara \& Gök, 2020; Klapproth et al., 2020) even it has a potential to be used various digital tools such as tablet and smartphone (Guo et al., 2020). Online learning cannot produce good results in developing countries like Pakistan, where a huge majority of students are not able to access the good internet facility due to technical as well as financial issues. This study addressed the effectiveness of online and challenges faced by students who are taking online classes. As per this study, $88 \%$ of students had not proper internet facility and they faced lots of internet issues and $65 \%$ students were not satisfied with online learning $85 \%$ students complaining about eye sight issue by taking online classes on devices $50 \%$ students were unable to manage the university affairs. All the students were facing same issues either they were school level or university level. Male and female students were facing same challenges in online classes.

Majority of the students have reservations about online/digital learning. Lack of access to internet facilities, lack of proper interaction and contact with students and instructors and ineffective technology were among the major challenges faced by higher education students of Pakistan. The sudden shift from traditional classrooms and face-to-face learning to online learning has resulted in a completely different learning experience for students. Most students do not have access to high speed or reliable internet services and are thus struggling with online learning. According to Ahmad (2020), students from less eveloped areas of former Fata, Balochistan, Chitral and Gilgit-Baltistan are devoid of internet facilities.

Due to the limited resources of educational institutions, only several institutions were able to introduce effective online classes during the initial days of pandemic. The research also indicated additional challenges faced by students like lack of campus socialization, teacher's response time. Responded also reported that online classes could not be applicable in Pakistan in future. Thus it can be concluded that online learning cannot produce effective results in developing countries like Pakistan, where a huge majority of students are not able to access the internet due to technical and financial issues.

One of the less discussed areas of online education is the need of affective factors (Kara \& Gök, 2020) such as motivation for online learning. In traditional classes, students usually actively participate in academic activities due to their face-to-face engagement with instructor and class fellows. 71.4\% of students reported that learning in the conventional classroom was more motivating than distance learning. As indicated by the majority of the students, they can manage their study time effectively online and can easily complete assignments in time but complete courses cannot be completed online.

To ensure an effective and productive online program, students must not only know how to cope up with the fast-paced online classes but they also need to have a sound computer and technological skills to learn from online lectures. For such students managing study time effectively is possible and they do not face any difficulty but when it comes to doing group assignments without face to face discussion with the group members, they face a lot of problems as reposted by $42.9 \%$ of respondents.

Most of the higher education students surveyed have reservations about online/digital learning. Lack of internet facilities,lack of proper interaction and contact with students and teachers, and ineffectiveness of technology are the main challenges facing higher education students in Pakistan. The sudden shift from traditional classroom and face-to-face learning to online learning has led to a completely different learning experience for students. Most students do not have access to high-speed or reliable internet service, so they are working hard to learn online. Students from the underdeveloped areas of former Fata, Balochistan, Chitral and GilgitBaltistan were deprived of internet facilities (Ahmad, 2020).

Due to the limited resources of educational institutions, only a few were able to launch effective online courses in the first months of the 19th International Cooperation Initiative. The study also shows that students 
face other challenges, such as lack of campus socialization, group learning problems and teacher response time. Survey participants also reported that traditional classroom learning was more effective than online learning or distance education. Therefore, it can be concluded that online learning does not produce effective results in less developed countries such as Pakistan, as the vast majority of students do not have access to the internet due to technical and monetary issues.

One of the less discussed areas of online education is the need for motivation for online learning. In traditional courses, students are usually actively involved in academic activities because they have face-to-face contact with lecturers and class fellows. $65.3 \%$ of students reported that the online learning is not effective. As most students have shown, they cannot effectively manage their study time online and cannot manage easily tasks in time. In order to ensure an effective and productive online program, students must not only know how to cope with fast-paced online courses, but they also need to have sound computer and technical skills to learn from seminars. Currently it is not possible for students to cope with such issues, students are facing many challenges in online learning and it is impossible to continue this system in Pakistan. If all these issues overcome then might be taking online classes for students could be fruitful.

\section{I. Recommendations}

Based on the results of the study, the following suggestions were made:

- Institutions that offer online courses or programs should make an effort to present to faculty the research about the efficacy of fully online and blended learning for achieving student learning outcomes. Many faculty are either unaware of or unconvinced by the research findings that fully online courses produce learning gains that are indistinguishable from those produced in fully face-to-face environments and that blended instruction has stronger learning outcomes than either mode alone. It should be a critical function of centers for teaching and learning at institutions with online courses or programs to present this evidence to faculty as part of any training in instructional design or use of tools for online teaching.

- Institutions that offer online courses or programs should provide incentives to faculty to redesign classroom-based courses for the online environment. Stipends and especially course release time are effective motivators for faculty.

- Researchers studying online teaching and learning should prioritize collecting data about the efficacy of tools, technologies, and practices for which the evidence base is not yet robust. In particular, data on the services provided by student success management systems such as course suggestions and early-alert systems would be valuable.

- Institutions and academic units should provide-and actively promote-training for students in the use of technologies that students will use in their courses. Students will inevitably use many tools and technologies, both commercially available (such as the Microsoft Office and Google Drive suites) and institutionally specific (such as the LMS). Many students feel unprepared to use institutionally specific technology, and some even feel unprepared to use commercial software. Regardless of the number or size of online courses or programs at an institution, technology is critical to student success, so this lack of knowledge and confidence is a major point of failure for students. This is comparatively easily remedied, however: Institutions should identify the most critical training needs among the student body and then provide and actively promote training opportunities in these areas. Faculty are critical to improving student technology literacy by encouraging or even requiring students to attend the trainings.

- Institutions that offer online courses or programs should develop reward systems that encourage innovation in teaching. At research institutions particularly, though not exclusively, innovation in teaching is not well rewarded in tenure and promotion processes. Faculty who have more confidence in their classroom management skills are more likely to encourage or require students to use computing devices in the classroom. This confidence comes naturally with age and with a greater number of years in a faculty position. This confidence should also come from knowledge that the institution's policies regarding evaluation of teaching support the faculty member in experimentation and innovation with technology in the classroom and online. 


\section{References}

Adnan, M., \& Anwar, K. (2020). Online learning amid the COVID-19 pandemic: Students' perspectives. Journal of Pedagogical Sociology and Psychology, 2(I), 45-5 I. https://doi.org/I 0.33902/JPSP. 202026I 309

Ahmad, I. (2020, April 5). Fata and the internet. Retrieved from The News: https://www.thenews.com.pk/print/639470-fata-and-the-internet

Ali, I. (2020). COVID-19 in Pakistan: Fill the gaps or brace for impact. The Express Tribun. https://tribune.com.pk/story/2 183684/I-covid- I 9-pakistan-fill-gaps-brace-impact/

COVID-I 9 Stats. (2020). Statistics. Retrieved from National Command Operation Center: https://ncoc.gov.pk/

Gilbert, B. (20I5). Online learning revealing the benefits and challenges. Education Masters. https://fisherpub.sjfc.edu/education_ETD_masters/303

Guo, J., Huang, F., Lou, Y., \& Chen, S. (2020). Students' perceptions of using mobile technologies in informal English learning during the COVID-19 epidemic: A study in Chinese rural secondary schools. Journal of Pedagogical Research, 4(4), 475-483. https://doi.org/I 0.33902/JPR.2020063786

Jaques, D., \& Salman, G. (2007). Learning in groups: A handbook for face to face and on line environments (4th Edition). London:Routledge

Karademir, A., Yaman, F., \& Saatçioğlu, Ö. (2020). Challenges of higher education institutions against COVID19: The case of Turkey. Journal of Pedagogical Research, 4(4), 453-474. https://doi.org// 0.33902/JPR.2020063574

Kara, A., \& Gök, A. (2020). Positive and negative affect during a pandemic: Mediating role of emotional regulation strategies. Journal of Pedagogical Research, 4(4), 484-497. https://doi.org// 0.33902/JPR.2020064452

Klapproth, F., Federkeil, L., Heinschke, F., \& Jungmann, T. (2020). Teachers' experiences of stress and their coping strategies during COVID-I9 induced distance teaching. Journal of Pedagogical Research, 4(4), 444-452. https://doi.org/ I0.33902/JPR.2020062805

Saqlain, M., Munir, M. M., Ahmed, A., Tahir, A. H., \& Kamran, S. (2020). Is Pakistan prepared to tackle the coronavirus epidemic? Drugs \& Therapy Perspectives, 36, 213-2I4.

Williams, K. C., Morgan, K., \& Cameron, B. A. (20II). How do students define their roles and responsibilities in online learning group projects? Distance Education 32(I), 49-62.

World Health Organization [WHO] (2020). Coronavirus. https://www.who.int/health-topics/coronavirus

$\mathrm{Wu}$, Z. (2020). How a top Chinese university is responding to coronavirus. Retrieved from World Economic Forum:https://www.weforum.org/agenda/2020/03/coronavirus-china-the-challenges-ofonline-learning-foruniversities/

Zhong, R. (2020, March 17). The coronavirus exposes education's digital divide. New York Times: https://www.nytimes.com/2020/03/I7/technology/china-schools-coronavirus.html 